\title{
Risk factors for diarrhea hospitalization in Bangladesh, 2000-2008: a case-case study of cholera and shigellosis
}

\author{
Danny V Colombara ${ }^{1 *}$, Abu SG Faruque ${ }^{2}$, Karen D Cowgill ${ }^{3,4}$ and Jonathan D Mayer ${ }^{1}$
}

\begin{abstract}
Background: Cholera and shigellosis are endemic on the Indian subcontinent. Our objective was to identify cholera-specific risk factors distinct from shigellosis risk factors.

Methods: We conducted a case-case study among hospitalized diarrheal patients, comparing those with cholera and shigellosis in International Centre for Diarrhoeal Disease Research, Bangladesh (icddr,b) hospitals in Matlab (rural) and Dhaka (urban) between January 1, 2000 and December 31, 2008.

Results: Multivariable Poisson regression models revealed that having more than nine years of education, compared to no education, was associated with a 39\% (adjusted Risk Ratio [aRR] $=0.61,95 \%$ confidence interval [Cl]: 0.40-0.93) decreased risk for cholera hospitalization in Matlab and a 16\% (aRR $=0.84,95 \%$ Cl: 0.75-0.94) decreased risk in Dhaka. Having a family member with diarrhea in the past seven days increased cholera hospitalization risk by $17 \%(\mathrm{aRR}=1.17,95 \% \mathrm{Cl}: 1.09-1.26)$ in Matlab.
\end{abstract}

Conclusions: Further studies are needed to elucidate the pathway through which education impacts cholera risk in order to create targeted interventions in cholera-endemic areas. Interventions seeking to reduce transmission and facilitate hygienic practices among family members of index cases with diarrhea should be considered, especially in rural cholera endemic settings.

Keywords: Cholera, Shigellosis, Epidemiology, Bangladesh

\section{Background}

Cholera is a diarrheal disease caused by infection with Vibrio cholerae bacteria. Since 1817 the world has endured a series of cholera pandemics [1,2]. The seventh pandemic, which started in the early 1960s, appeared to be waning at the turn of the millennium, but has since developed new vigor. The global case fatality rate, which was $1.3 \%$ in 2011 [3], has remained relatively constant over the last 10 years, but absolute cholera-associated morbidity and mortality have increased dramatically as reported annual cases have more than doubled during this period [3-5].

Although much of the world faces cholera risk during pandemics, due to aquatic reservoirs [6], cholera has been endemic in Bangladesh for centuries [7] and is

\footnotetext{
*Correspondence: dvc2@uw.edu

'Department of Epidemiology, University of Washington, Seattle, WA, USA Full list of author information is available at the end of the article
}

hyperendemic in rural Bangladesh [8]. In recent years, studies in Bangladesh have demonstrated that $V$. cholerae is the enteric pathogen most strongly linked to floodassociated diarrhea epidemics [9], and suggested that genetic susceptibility $[10,11]$ and socioeconomic status (SES) may be important determinants of cholera risk [10]. Studies have also reported that familial relatedness and retinol deficiency may be risk factors [11], as well as high population density [12], low education levels [12], and the proximity of household clusters to contaminated surface water [12-14]. These are in addition to well-established risk factors such as young age and poor sanitary conditions.

Most cholera risk factor studies have used case-control designs $[10,15,16]$, which may have identified general diarrhea risk factors in conjunction with cholera-specific risk factors. A case-case study design could complement these prior studies by identifying cholera-specific risk factors. Case-case study designs are able overcome two perennial 
challenges to case-control studies: selection bias and recall bias. Compared to case-control studies, selection bias may be reduced because both the referent cases and the cases of interest are selected in the same way and represent the same population [17]. For example, in surveillance data, both sets of cases tend to be representative of those with more severe illness $[18,19]$ and are likely to have the same disposition to seek medical care [19]. Casecase studies are also less susceptible to recall bias than case-control studies because both the referent group and the cases of interest would have their recall stimulated by similar events $[18,20]$. Since the referent group would share some diarrhea risk factors, this design is not well suited for identifying general risk factors [17], but may enable the identification of cholera-specific risk factors. Finally, case-case studies can use regularly collected surveillance data, thereby making them faster and less expensive than case-control studies $[17,18]$. However, the study design also has weaknesses that must be accounted for in the interpretation of the results. Specifically, because the referent is also diseased, risk estimates cannot be extrapolated to the general population [20]. For example, the strength of association will be underestimated if a given exposure is a risk factor for both sets of cases. Conversely, the strength of association would be inflated if a given exposure was protective among the referent cases [18]. We are prevented from obtaining unbiased assessment of exposures common to both [17].

Shigellosis offers itself as an ideal referent for a casecase study of cholera since it also has a bacterial etiology (Shigella spp.) and is endemic in Bangladesh [21]. The epidemiology of shigellosis and cholera are both similar (e.g., they have seasonality $[22,23]$ and young children are at greatest risk $[24,25]$ ) and different (e.g., a low infectious dose of shigella [26] enables direct personto-person transmission [27]), which may lead to the identification of disease-specific risk factors and disease control interventions.

Our objective was to identify cholera-specific risk factors distinct from shigellosis risk factors. We therefore conducted a case-case study among hospitalized diarrheal patients, comparing those with cholera to those with shigellosis.

\section{Methods}

\section{Study design and setting}

We conducted a hospital-based case-case study using the International Centre for Diarrhoeal Disease Research, Bangladesh (icddr,b) Diarrhoeal Diseases Surveillance System (DDSS) in Matlab and Dhaka hospitals.

We selected a case-case study design for the reasons outlined in the introduction above.

The DDSS employs icddr,b hospital staff to systematically record clinical, socioeconomic, and demographic data from diarrheal patients presenting to icddr,b hospitals prior to the patients receiving their diagnoses. All DDSS patients have their stool tested for enteric pathogens, including V. cholerae, Shigella, Salmonella, rotavirus, amoeba, and Giardia species. Regardless of etiology, we considered any case of diarrhea that required hospital treatment to be severe, and focused on those cases because they are of greatest clinical importance.

The Matlab hospital DDSS is part of a larger Health and Demographic Surveillance System (HDSS) created in Matlab sub-district, a rural area in east-central Bangladesh, in 1966. The HDSS employs Community Health Research Workers to record demographic, mortality, migration, and other relevant data through bimonthly visits to each household. The Matlab HDSS catchment area covers more than 200,000 residents, with all HDSS diarrheal patients treated at the icddr,b enrolled into the DDSS. Due to river and road access, and icddr,b's wellestablished relationship the with the community, use of its facilities is assumed to be homogenous throughout the study area [28].

Dhaka is the largest city in Bangladesh, with large numbers of residents living in substandard housing (slums). Since 1996, two percent of patients at the Dhaka Hospital have been systematically enrolled in the DDSS [9]. Due to the hospital's location within the city limits, its services are considered to be accessible to all city residents. The administrative and clinical staff in Matlab and Dhaka received equivalent training to ensure comparability of care and DDSS data quality. In both settings, icddr,b hospitals provide free, high-quality diarrhea treatment.

In this case-case analysis, rural dwellers were defined as Matlab patients who were registered with the Matlab HDSS and self-reported currently living in a village. Urban dwellers were defined as Dhaka patients who selfreported currently living in slums or high-density mixed-use and residential areas.

\section{Study population}

We analyzed in-patient and out-patient data from patients who entered icddr,b hospitals for diarrhea treatment between January 1, 2000 and December 31, 2008. Since risk factors and necessary disease control measures among children under five may be different from older individuals, their risk factors were analyzed separately [29]. We also excluded those with missing age data, non-rural Matlab patients, non-urban Dhaka patients, those with neither cholera nor shigellosis, and those with enteric co-infections. Use of anonymized data prevented us from assessing if there were multiple admissions of the same patient.

\section{Cholera and Shigellosis definitions}

$V$. cholerae positivity was defined by the detection of $V$. cholerae O139 (Bengal), $V$. cholerae O1 El Tor Ogawa, $V$. 
cholerae O1 El Tor Inaba, $V$. cholerae O1 Classical Ogawa, or V. cholerae O1 Classical Inaba. Shigella spp. infection was defined by the detection of $S$. dysenteriae, S. flexneri, S. boydii, or S. sonnei. There were no changes in laboratory testing methods for $V$. cholerae or Shigella spp. during the study period.

\section{Data analysis}

The prevalence of potential correlates of diarrhea among hospitalized patients with cholera and shigellosis at icddr,b hospitals were compared. Self-reported sociodemographic characteristics included age, sex, number of household members, education, household income, urban residence, residence in a slum community, homeownership, and presence of concrete floors in the home. Education was defined as the patient's education (for those $\geq 15$ years old) or the mother's education (for those $<15$ years old). Selfreported water and sanitation characteristics included the patient's household having improved toilet facilities [30], distance from the kitchen to drinking water (reported in feet and converted to meters for analysis), source of water, and drinking water treatment. Source of water was constructed by combining drinking and bathing water variables; if these were different, the least safe source was used for the analysis. Surface water was defined as that from a pond, river, or ditch. "Other" water treatment included use of tablets, filters, and sieves. Data regarding the source of water used for food preparation was unavailable for this analysis. Other potential correlates included the distance to the hospital (self-reported in miles and converted to $\mathrm{km}$ for analysis), the presence of a family member with diarrhea in the past week, and the season.

Clinical characteristics included general physical condition and clinical dehydration on admission as assessed by medical staff, self-reported days with diarrhea prior to admission, and the number of stools and history of vomiting in the 24 hours prior to admission. Data regarding patient deaths, if any, were not available.

\section{Risk factor analysis}

Assessed sociodemographic risk factors included age, sex, the number of household members, years of education, monthly household income (converted from Taka using the rate of exchange at the study period's midpoint [31]), residence in a slum community, homeownership, and the presence of concrete floors in the home. Risk factors related to sanitation and water included improved toilet facilities, distance from the kitchen to the drinking water source (10-m increments), water source, and drinking water treatment. The distance from the home to the hospital $(\mathrm{km})$ and the presence of a family member with diarrhea in the past seven days were also assessed.

\section{Statistical methods}

We used Poisson regression with robust variance estimates to calculate risk ratios (RR) and 95\% confidence intervals $(95 \% \mathrm{CI})$ for cholera hospitalization risk factors [32]. The dependent variable in the regression model was cholera hospitalization (vs. shigellosis hospitalization) and the independent variables are listed under "Risk factor analysis" above. Due to substantial differences between Dhaka and Matlab, all regression analyses were stratified by urban or rural status. Only potential risk factors with less than $5 \%$ missing data were evaluated. Stata/IC 13.1 (StataCorp LP, College Station, TX) was used for all analyses. All $P$-values are two-sided.

(Statistically significant univariable predictors $(p<0.10)$ were considered candidates for the multivariable model. Predictors with a RR between 0.9 and 1.1 were excluded from consideration for the multivariable model due to small effect sizes. Strata with less than ten observations were also excluded from consideration for the multivariable model. We used variance inflation factors (VIF) to assess collinearity among the multivariable candidates. In the event of collinearity (VIF $\geq 10$ ), we considered only the more biologically plausible predictor.

We built a multivariable regression model by sequentially adding and testing statistically significant candidates from the univariable analysis, in order of effect size. Continuous variables were retained in the model if the Wald test was significant $(p<0.05)$. A categorical variable was retained if the composite linear Wald test of all the variable's strata and the Wald test for at least one individual stratum indicator variable was significant $(p<0.05)$.

Cholera seasonality [1] and age were included in the multivariable model as a priori adjustment variables. The seasonality adjustment variable was comprised of a restricted cubic spline of the day of the year on the date of visit (1-366). The spline had seven knots and was created to prevent the imposition of artificial categories or parameters on the data $[33,34]$.

\section{Ethics statement}

The Research Review Committee (RRC) and Ethical Review Committee (ERC) of the icddr,b approved the hospital surveillance activities. Due to the high proportion of illiterate patients, the icddr,b RRC and ERC waived the need for written informed consent and approved the use of oral informed consent for all participants. Parents, guardians, next of kin, or caretakers provided oral informed consent for minors. icddr,b staff documented consent in the surveillance database. All data analyses were performed using anonymized patient medical records. The University of Washington Human Subjects Division/Institutional Review Board determined this research to be exempt from human subjects review because it did not fall under the definition of human subjects research under 45CFR46. 
Table 1 Sociodemographic, water and sanitation, and other potential correlates of hospitalization for diarrhea among icddr,b patients $\geq 5$ years old, Bangladesh, 2000-2008

\begin{tabular}{cccc}
\hline & $\begin{array}{c}\text { Cholera } \\
(\mathrm{n}=3,072)\end{array}$ & & $\begin{array}{c}\text { Shigella } \\
(\mathrm{n}=638)\end{array}$ \\
\cline { 2 - 3 } \cline { 5 - 6 } & $\mathrm{N} \quad \%^{\mathrm{a}}$ & & $\mathrm{N} \%^{\mathrm{a}}$ \\
\hline
\end{tabular}

Sociodemographic

Age (yrs.)

5-15

$16-25$

26-35

$36-45$

$46+$

Female sex

No. household members

$<3$

4

5

6

$7+$

Education $^{\mathrm{b}}$

None

$1-5$ years

6-9 years

$>9$ years

Household income (USD/mo.)

$>84$

50-84

34-49

$\leq 34$

Urban residence

Residence in a slum

Homeownership

Cement floor in home

Sanitation \& water

Improved toilet facilities

Distance to drinking water (meters)

0

$<10$

10-19

20-50

$>50$

Source of water

Tap

Tube well

Surface

$\begin{array}{cccc}772 & 25 & 96 & 15 \\ 999 & 33 & 143 & 22 \\ 530 & 17 & 89 & 14 \\ 326 & 11 & 84 & 13 \\ 445 & 14 & 226 & 35 \\ 1479 & 48 & 335 & 53\end{array}$

$554-18-124=19$

$\begin{array}{llll}580 & 19 & 111 & 17\end{array}$

$\begin{array}{llll}659 & 21 & 140 & 22\end{array}$

$\begin{array}{llll}484 & 16 & 98 & 15\end{array}$

$\begin{array}{llll}792 & 26 & 165 & 26\end{array}$

$\begin{array}{llll}2391 \quad 78 & 447 \quad 70\end{array}$

$\begin{array}{llll}391 & 13 & 109 & 17\end{array}$

$\begin{array}{llll}219 & 7 & 52 & 8\end{array}$

$\begin{array}{llll}71 & 2 & 30 & 5\end{array}$

$\begin{array}{llll}1205 & 39 & 324 & 51\end{array}$

$\begin{array}{llll}1274 & 42 & 216 & 34\end{array}$

$\begin{array}{llll}400 & 13 & 70 & 11\end{array}$

$\begin{array}{llll}193 & 6 & 28 & 4\end{array}$

$\begin{array}{llll}2014 & 666 \quad 189 \quad 30\end{array}$

$\begin{array}{llll}342 & 17 & 25 & 13\end{array}$

$\begin{array}{llll}1219 & 40 & 463 & 73\end{array}$

$\begin{array}{llll}1446 & 47 & 426 & 67\end{array}$

$1414 \quad 46 \quad 188 \quad 30$

$\begin{array}{llll}477 & 16 & 72 & 11\end{array}$

$\begin{array}{llll}1619 & 53 \quad 319 \quad 50\end{array}$

$\begin{array}{llll}403 & 13 & 90 & 14\end{array}$

$\begin{array}{llll}324 & 11 & 82 & 13\end{array}$

$\begin{array}{llll}249 & 8 & 75 & 12\end{array}$

$\begin{array}{llll}1787 & 58 & 175 & 28\end{array}$

$\begin{array}{llll}318 & 10 & 66 & 10\end{array}$

$\begin{array}{llll}965 & 31 & 396 & 62\end{array}$
Table 1 Sociodemographic, water and sanitation, and other potential correlates of hospitalization for diarrhea among icddr,b patients $\geq 5$ years old, Bangladesh, 2000-2008 (Continued)

\begin{tabular}{lcccc}
\hline Drinking water treatment & 2312 & 75 & 530 & 83 \\
None & 694 & 23 & 91 & 14 \\
Boiling & 66 & 2 & 17 & 3 \\
Other & & &
\end{tabular}

Other potential correlates

Distance to hospital (km)

$\leq 3$

$>3 \& \leq 5$

$>5 \& \leq 7$

$>7$

$\begin{array}{cccc}281 & 9 & 143 & 22 \\ 475 & 15 & 169 & 26 \\ 422 & 14 & 86 & 14 \\ 1892 & 62 & 240 & 38 \\ 478 & 16 & 42 & 7\end{array}$

Family member with diarrhea

in past week

Season

$\begin{array}{lcccc}\text { Hot: March - June } & 1177 & 38 & 180 & 28 \\ \text { Rain: June - October } & 1377 & 45 & 255 & 40 \\ \text { Dry/Cool: October - March } & 518 & 17 & 203 & 32\end{array}$

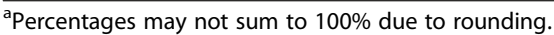

${ }^{b}$ Education of patient for those $\geq 15$ years of age; education of mother for those $<15$ years old.

'Water from rivers, ponds, and ditches was categorized as surface water.

\section{Results}

\section{Study population}

We excluded those with missing age $(n=45)$, indeterminate rural or urban residential status $(n=7,242)$, and age less than five years $(n=14,515)$. Of the remaining 11,369 patients, we excluded the $54 \%(n=6,096)$ who had no pathogen detected, 3\% $(\mathrm{n}=365)$ who had laboratoryconfirmed coinfection of $V$. cholerae or Shigella spp. with other known pathogens, and $11 \%(\mathrm{n}=1,198)$ who were infected with neither $V$. cholerae nor Shigella spp. Our final population was thus the $27 \%(\mathrm{n}=3,072)$ who were hospitalized with cholera and the $6 \%(\mathrm{n}=638)$ who were hospitalized with shigellosis. The refusal rate for participation in the DDSS was not available.

\section{Characteristics of hospitalized cholera and shigellosis cases}

Compared to hospitalized shigellosis patients, hospitalized cholera patients were younger (median age, 24 vs. $35)$, more likely to be uneducated (78\% vs. $70 \%)$, and less likely to be in the highest income bracket (39\% vs. 51\%) (Table 1). Cholera patients were also more likely to live in an urban area (66\% vs. $30 \%)$, less likely to be homeowners ( $40 \%$ vs. $73 \%$ ), and less likely to have cement floors in their homes (47\% vs. $67 \%)$. With regard to sanitation and water, cholera patients were more likely to have improved toilet facilities ( $46 \%$ vs. $30 \%)$, to have a drinking water source 
within 10 meters of the kitchen (69\% vs. $61 \%$ ), to use tap water $(58 \%$ vs. $28 \%)$, and to treat their drinking water $(25 \%$ vs. $17 \%$ ). In addition, cholera patients lived further from icddr,b hospitals and were more likely to have had a family member with diarrhea in the past week.

Regarding clinical characteristics, hospitalized cholera patients were more likely to present at icddr,b hospitals in a worse than normal general condition ( $85 \%$ vs. $36 \%$ ) and to have clinical dehydration ( $94 \%$ vs. $47 \%$ ) (Table 2). They were also more likely to present to a hospital within one day of diarrhea onset ( $72 \%$ vs. $45 \%$ ) and to have stool without blood or mucus ( $96 \%$ vs. $40 \%$ ). In the 24 hours prior to admission, they were somewhat more likely to

Table 2 Clinical characteristics of patients $\geq \mathbf{5}$ years old with hospitalized diarrhea in icddr,b hospitals, Bangladesh, 2000-2008

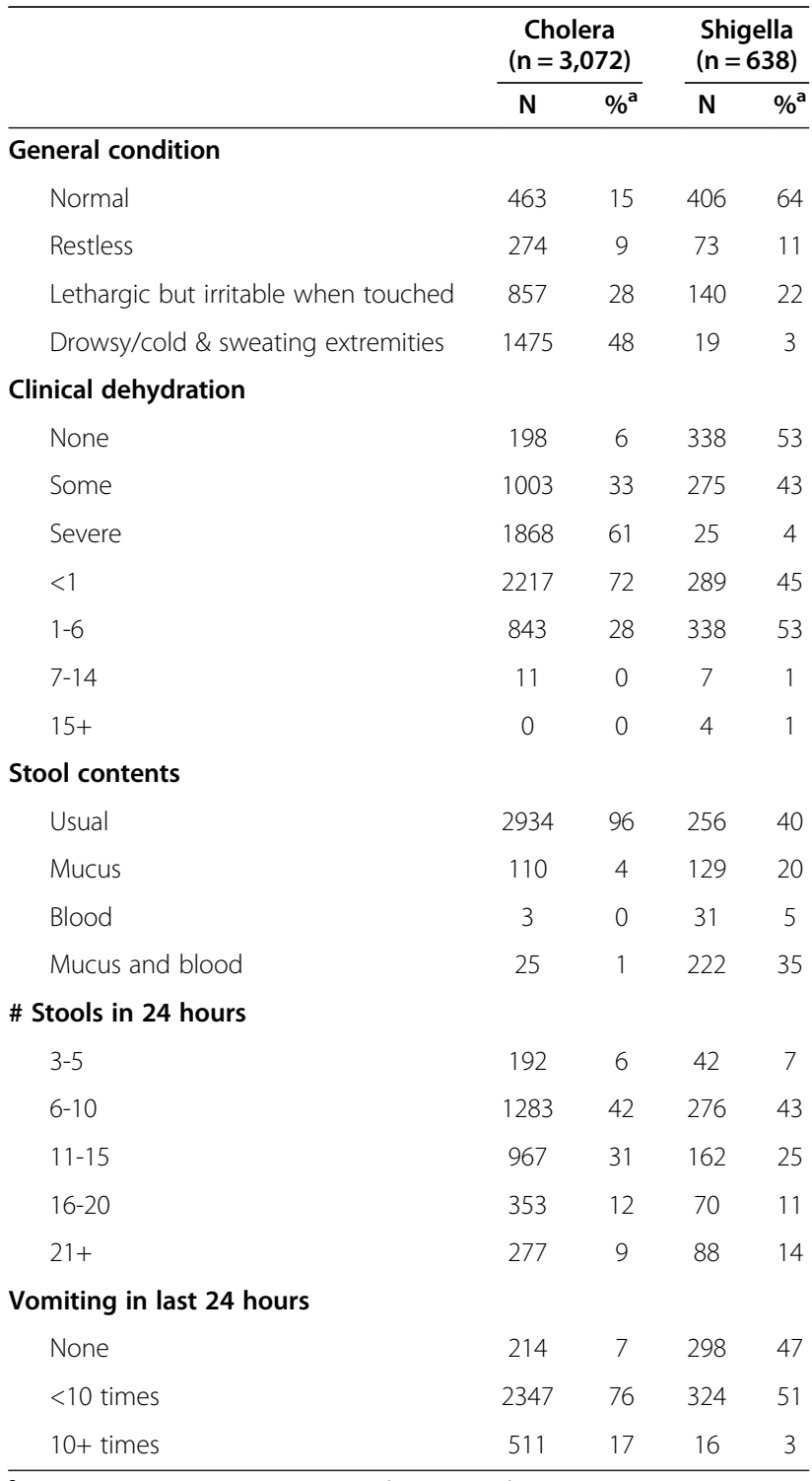

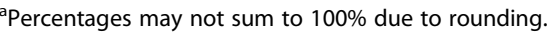

have 15 or fewer stools $(79 \%$ vs. $75 \%)$ and much more likely to have vomited ( $93 \%$ vs. $53 \%$ ).

\section{Risk factor analysis}

Univariable risk estimates for icddr,b diarrheal patients, stratified by rural or urban residence, are reported in Table 3. All variables had less than $5 \%$ missing data and there was no evidence of collinearity among the variables. Education, household income, homeownership, having cement floors in the home, sources of water, and having a family member with diarrhea in the past week were statistically significant and had a RR less than 0.90 or greater than 1.10 in the rural setting. In the urban setting, only education was significant and had a RR less than 0.90 or greater than 1.10

In the rural multivariable model, risk for cholera hospitalization decreased with increasing levels of education, with those having more than nine years of education experiencing approximately 40\% reduced risk (adjusted Risk Ratio $[\mathrm{aRR}]=0.61,95 \%$ confidence interval $[\mathrm{CI}]$ : 0.40-0.93) compared to those with no education (Table 4). Those who had a family member with diarrhea in the past week had a $17 \%$ increase in risk for cholera hospitalization ( $\mathrm{aRR}=1.17,95 \%$ CI: $1.09-1.26)$.

In the urban multivariable model, education also was associated with cholera hospitalization risk $(P=0.07)$, with those having more than nine years of education experiencing $16 \%$ reduced risk ( $\mathrm{aRR}=0.84,95 \% \mathrm{CI}$ : 0.750.94), compared to those without an education (Table 4). Based upon our predetermined criteria, no other variables were included in the model except for age and season, the a priori adjustment variables.

We performed cross-tabulations of sources of water and improved toilet facilities, stratified by urban and rural residence and education level (Table 5). We did this in order to explore the relationship between water source and education variables, both of which were expected to be correlated with cholera hospitalization. In both settings, higher levels of education were associated with improved toilet facilities. The majority of those with improved toilets in Matlab continued to use surface water, but the majority of those with improved toilets in Dhaka used tap water.

\section{Discussion}

Higher levels of education were correlated with reduced risk for cholera hospitalization in both rural and urban Bangladesh. In addition, having a family member with diarrhea in the past week was associated with increased risk among rural dwellers.

The association between increasing education levels and decreasing cholera hospitalization risk was expected based on prior studies in Matlab [12,29]. There is evidence from other contexts that shigellosis may also be associated with low levels of education [35]. Therefore, 
Table 3 Univariable risk factor analysis for cholera compared to shigellosis among patients $\geq \mathbf{5}$ years old hospitalized for diarrhea, icddr,b hospitals, Bangladesh, 2000-2008

\begin{tabular}{|c|c|c|c|c|c|c|}
\hline & \multicolumn{3}{|c|}{ Rural univariable } & \multicolumn{3}{|c|}{ Urban univariable } \\
\hline & \multicolumn{3}{|c|}{$(n=1,507)$} & \multicolumn{3}{|c|}{$(n=2,203)$} \\
\hline & Cholera/Total (\%) & RR & $95 \% \mathrm{Cl}$ & Cholera/Total (\%) & RR & $95 \% \mathrm{Cl}$ \\
\hline \multicolumn{7}{|l|}{ Sociodemographic } \\
\hline Age (10 yr. intervals) & - & 0.94 & $(0.92-0.95)$ & - & 0.97 & $(0.96-0.98)$ \\
\hline Female sex & $588 / 845(70)$ & 0.98 & $(0.92-1.05)$ & $891 / 969$ (92) & 1.01 & $(0.98-1.04)$ \\
\hline No. household members & - & 1.03 & $(1.01-1.04)$ & - & 1 & $(1.00-1.00)$ \\
\hline \multicolumn{7}{|l|}{ Education $^{a, b}$} \\
\hline None & 782/1095 (71) & 1 & - & 1609/1743 (92) & 1 & - \\
\hline $1-5$ years & $181 / 268(68)$ & 0.95 & $(0.86-1.04)$ & 210/232 (91) & 0.98 & $(0.94-1.02)$ \\
\hline 6-9 years & $84 / 120(70)$ & 0.98 & $(0.87-1.11)$ & 135/151 (89) & 0.97 & $(0.92-1.02)$ \\
\hline$>9$ years & $11 / 24(46)$ & 0.64 & $(0.41-0.99)$ & $60 / 77(78)$ & 0.84 & $(0.75-0.95)$ \\
\hline \multicolumn{7}{|l|}{ Household income (USD/mo.) $)^{c}$} \\
\hline$>84$ & $416 / 647(64)$ & 1 & - & 789/882 (89) & 1 & - \\
\hline $50-84$ & 494/657 (75) & 1.17 & $(1.09-1.26)$ & 780/833 (94) & 1.05 & $(1.02-1.08)$ \\
\hline $34-49$ & $127 / 168(76)$ & 1.18 & $(1.06-1.30)$ & $273 / 302(90)$ & 1.01 & $(0.97-1.06)$ \\
\hline$\leq 34$ & $21 / 35(60)$ & 0.93 & $(0.71-1.23)$ & $172 / 186(92)$ & 1.03 & $(0.99-1.08)$ \\
\hline Residence in a slum & - & - & & $342 / 367(93)$ & 1.02 & $(0.99-1.06)$ \\
\hline Homeownership & $1045 / 1480(71)$ & 1.41 & $(0.96-2.08)$ & 174/202 (86) & 0.94 & $(0.88-0.99)$ \\
\hline Cement floor in home & $70 / 122(57)$ & 0.80 & $(0.69-0.94)$ & 1555/1714 (91) & 0.97 & $(0.94-0.99)$ \\
\hline \multicolumn{7}{|l|}{ Sanitation \& Water } \\
\hline Improved toilet facilities & 78/122 (64) & 0.90 & $(0.79-1.04)$ & 1336/1480 (90) & 0.96 & $(0.94-0.99)$ \\
\hline Dist. to drinking water (10 m increments) & - & 1.01 & $(1.00-1.01)$ & - & 1 & $(1.00-1.01)$ \\
\hline \multicolumn{7}{|l|}{ Source of water } \\
\hline Tap & $3 / 3(100)$ & 1.50 & $(1.34-1.67)$ & 1784/1959 (91) & 0.96 & $(0.93-1.00)$ \\
\hline Tube well & 108/162 (67) & 1 & - & 210/222 (95) & 1 & - \\
\hline Surface $^{d}$ & $947 / 1342(71)$ & 1.06 & $(0.94-1.19)$ & 18/19 (95) & 1.00 & $(0.90-1.12)$ \\
\hline \multicolumn{7}{|l|}{ Drinking water treatment } \\
\hline None & $1000 / 1426(70)$ & 1 & - & 1312/1416 (93) & 1 & - \\
\hline Boiling & $8 / 15(53)$ & 0.76 & $(0.47-1.22)$ & $686 / 770(89)$ & 0.96 & $(0.93-0.99)$ \\
\hline Other & $50 / 66(76)$ & 1.08 & $(0.94-1.24)$ & 16/17 (94) & 1.02 & $(0.90-1.15)$ \\
\hline \multicolumn{7}{|l|}{ Other potential correlates } \\
\hline Distance to hospital (km) & - & 1.02 & $(1.01-1.02)$ & - & 1 & $(1.00-1.00)$ \\
\hline Family member with diarrhea in past week & $162 / 194(84)$ & 1.22 & $(1.14-1.32)$ & $316 / 326(97)$ & 1.07 & $(1.05-1.10)$ \\
\hline
\end{tabular}

${ }^{a}$ Education of patient for those $\geq 15$ years of age; education of mother for those $<15$ years old.

${ }^{\mathrm{b}}$ Statistical evidence of a decreasing trend among urban residents $(P=0.002)$.

'Statistical evidence of an increasing trend among rural residents $(P=0.003)$.

${ }^{\mathrm{d}}$ Water from rivers, ponds, and ditches was categorized as surface water.

given our case-case study design, the magnitude of the risk reduction attributable to higher education levels may be attenuated compared to what would be seen with populationbased controls. The exact mechanism(s) through which education affects cholera risk have not been determined and are worthy of further study. However, the results of the exploratory cross tabulations of toilet facilities and water sources by education level suggest that part of the protective effect of higher education may be mediated through these variables.

The increased risk associated with family members having had diarrhea in the past week was expected, and is likely due to household-level exposures to $V$. choleraecontaminated water and food [36]. In addition, family members have similar genetics and may share an elevated susceptibility to cholera infection $[10,11,37]$ as well 
Table 4 Multivariable risk factor analysis for cholera compared to shigellosis among patients $\geq \mathbf{5}$ years old hospitalized for diarrhea, icddr,b hospitals, Bangladesh, 2000-2008

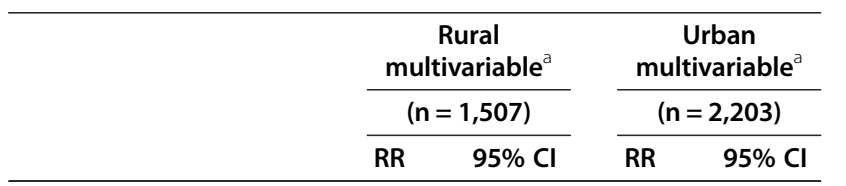

\section{Sociodemographic}

\section{Education}

$\begin{array}{lcccc}\text { None } & 1 & & 1 & \\ \text { 1-5 years } & 0.85 & (0.78-0.92) & 0.97 & (0.93-1.02) \\ \text { 6-9 years } & 0.86 & (0.76-0.97) & 0.96 & (0.91-1.01) \\ >9 \text { years } & 0.61 & (0.40-0.93) & 0.84 & (0.75-0.94)\end{array}$

Other potential correlates

\section{Family member with} diarrhea in past week

${ }^{a}$ Adjusted for a priori confounders (age and season) and other predictors in the model.

${ }^{\mathrm{b}}$ Education of patient for those $\geq 15$ years of age; education of mother for those $<15$ years old. There is statistical evidence of decreasing risk with increasing levels of education in both settings $(P<0.001)$. as severe cholera disease. However, unlike Shigella [27], which is easily passed from person-to-person, the contribution of person-to-person cholera transmission among family members remains unclear $[2,38]$.

Improved toilet facilities are generally considered to be strongly protective for cholera. However, we observed no substantial protective effect for cholera hospitalization as opposed to shigellosis hospitalization in either the rural (where few had improved toilet facilities) or the urban setting. This is most likely due to attenuation of the risk estimate because improved toilet facilities reduce the risk for multiple diarrhea etiologies. As mentioned above, the inability to identify general risk factors is a limitation of the case-case study design. However, it is also possible that homes with improved toilet facilities continued to have high levels of fecal contamination [39], thereby negating some of the potential benefit of the infrastructure.

Based on our previous study among children under five in which we compared those hospitalized with cholera to those hospitalized with all other diarrhea [29], we anticipated that low SES would be associated with increased risk for cholera hospitalization. However, household income, homeownership, and other measures of SES (except for education) were not significant in our multivariable models. This might be because SES is only related to cholera risk among children under five, or because SES impacts risk for cholera and shigellosis equally.

Table 5 Cross tabulations of toilet facilities and sources of water, stratified by urban and rural residence and education level

\begin{tabular}{|c|c|c|c|c|c|c|c|c|c|c|c|c|c|}
\hline \multirow[b]{4}{*}{ Education } & \multirow[b]{4}{*}{ Water source } & \multicolumn{4}{|c|}{ Rural } & \multirow[b]{4}{*}{ Total } & \multirow[b]{4}{*}{$P^{\mathrm{b}}$} & \multicolumn{4}{|c|}{ Urban } & \multirow[b]{4}{*}{ Total } & \multirow[b]{4}{*}{$P^{\mathrm{b}}$} \\
\hline & & \multirow{2}{*}{\multicolumn{2}{|c|}{$\begin{array}{c}\text { Improved } \\
\text { Toilet }\end{array}$}} & \multirow{2}{*}{\multicolumn{2}{|c|}{$\frac{\text { Unimproved }}{\text { Toilet }}$}} & & & \multirow{2}{*}{\multicolumn{2}{|c|}{$\begin{array}{c}\text { Improved } \\
\text { Toilet }\end{array}$}} & \multirow{2}{*}{\multicolumn{2}{|c|}{$\frac{\text { Unimproved }}{\text { Toilet }}$}} & & \\
\hline & & & & & & & & & & & & & \\
\hline & & $n$ & $\%^{a}$ & $\mathrm{n}$ & $\%^{a}$ & & & $\mathrm{n}$ & $\%^{a}$ & $\mathrm{n}$ & $\%^{a}$ & & \\
\hline & Tap & 3 & 0.2 & 0 & - & & & 1,391 & 63.2 & 568 & 25.8 & & \\
\hline \multirow[t]{3}{*}{ All levels } & Tube well & 43 & 2.9 & 119 & 7.9 & & & 81 & 3.7 & 141 & 6.4 & & \\
\hline & Surface & 76 & 5.0 & 1,266 & 84.0 & 1,507 & $<0.001$ & 5 & 0.2 & 14 & 0.6 & 2,200 & $<0.001$ \\
\hline & Tap & 1 & 0.1 & 0 & - & & & 1,007 & 57.8 & 525 & 30.2 & & \\
\hline \multirow[t]{3}{*}{ None } & Tube well & 12 & 1.1 & 71 & 6.5 & & & 66 & 3.8 & 126 & 7.2 & & \\
\hline & Surface & 49 & 4.5 & 962 & 87.9 & 1,095 & $<0.001$ & 4 & 0.2 & 13 & 0.7 & 1,741 & $<0.001$ \\
\hline & Tap & 1 & 0.4 & 0 & - & & & 181 & 78.0 & 27 & 11.6 & & \\
\hline \multirow[t]{3}{*}{$1-5$ years } & Tube well & 13 & 4.9 & 31 & 11.6 & & & 11 & 4.7 & 11 & 4.7 & & \\
\hline & Surface & 15 & 5.6 & 208 & 77.6 & 268 & $<0.001$ & 1 & 0.4 & 1 & 0.4 & 232 & $<0.001$ \\
\hline & Tap & 0 & - & 0 & - & & & 132 & 87.4 & 13 & 8.6 & & \\
\hline \multirow[t]{3}{*}{$6-9$ years } & Tube well & 13 & 10.8 & 13 & 10.8 & & & 3 & 2.0 & 3 & 2.0 & & \\
\hline & Surface & 10 & 8.3 & 84 & 70.0 & 120 & $<0.001$ & 0 & - & 0 & - & 151 & 0.016 \\
\hline & Tap & 1 & 4.2 & 0 & - & & & 71 & 93.4 & 3 & 3.9 & & \\
\hline \multirow[t]{2}{*}{$>9$ years } & Tube well & 5 & 20.8 & 4 & 16.7 & & & 1 & 1.3 & 1 & 1.3 & & \\
\hline & Surface & 2 & 8.3 & 12 & 50.0 & 24 & 0.037 & 0 & - & 0 & - & 76 & 0.103 \\
\hline
\end{tabular}


Given the substantial differences in the availability of improved toilets, sources of water, family income, home ownership, and numerous unmeasured geographic and social differences between Matlab and Dhaka, it is surprising that we found little evidence for differential transmission patterns. However, the increased risk for cholera hospitalization associated with having a family member with diarrhea in the past week was only a risk factor in the rural setting. One possible explanation for why this association is weaker in Dhaka may be that urban dwellers are more likely to eat and drink outside of their home, whereas Matlab residents are more likely to share the contaminated sources of food or drink. Unfortunately, we are unable to assess this with our data.

\section{Strengths and limitations}

The strengths of our study include reliable $V$. cholerae and Shigella spp. diagnosis by experienced clinical laboratories, methodical sampling, and a large sample size. The case-case study design is also a strength in that it isolates diarrhea risk factors unique to cholera hospitalization [17]. However, this study design is also limited in that cholera shares some risk factors with shigellosis, so our risk estimates are likely to be attenuated compared to those we would have obtained if we had used a population without diarrhea as a comparison group. Another limitation was the use of anonymized data, which prohibited us from identifying repeat patient visits and patients from the same family or household [11]. Both conditions would violate independence assumptions underlying our statistical analyses. However, based on the natural immunity and low rehospitalization rates reported in prior studies $[7,40]$, few repeat cholera visits would be expected. In addition, any family or household clustering effects are expected to be relatively small in comparison to the study sample size. The large number of patients with no pathogen detected is another limitation. Some of the patients excluded for having no pathogen detected may actually have had $V$. cholerae or Shigella infection, and excluding them may have biased our sample. Performing polymerase chain reaction (PCR) testing on a subsample of these patients' specimens might have given an indication of what proportion of cholera and shigellosis cases were misclassified on this account. However, this assumes that PCR is more sensitive than culture -.- whereas some evidence suggests it is not [41].

\section{Conclusions}

We report that lack of education is a risk factor specific for cholera hospitalization in both rural and urban Bangladesh. In addition, having a family member with diarrhea in the past seven days is a risk factor in rural Bangladesh. Further studies are needed to elucidate the pathway through which education impacts cholera risk in order to create targeted interventions in cholera-endemic areas. In addition, among rural families with an index case of diarrhea, interventions to facilitate hygienic practices should be assessed as a means to reduce the incidence of secondary cases at the household level.

\section{Abbreviations}

aRR: Adjusted risk ratio; Cl: Confidence intervals; DDSS: Diarrhoeal diseases surveillance system; ERC: Ethical Review Committee; HDSS: Health and demographic surveillance system; Icddr, b: International Centre for Diarrhoeal Disease Research, Bangladesh; ORS: Oral rehydration solution; PCR: Polymerase chain reaction; RR: Risk ratios; RRC: Research Review Committee; SES: Socioeconomic status; VIF: Variance inflation factors.

\section{Competing interests}

The authors declare that they have no competing interests.

\section{Authors' contributions}

DVC, ASGF, KDC, and JDM conceived and designed the analyses. DVC, KDC, and ASGF analyzed the data. DVC prepared the initial draft of the manuscript and ASGF, KDC, and JDM made substantial contributions to subsequent revisions. All authors read and approved the final manuscript.

\section{Acknowledgements}

We would like to thank Mr. Abdul Malek for preparation of the data files and Dr. Dilruba Nasrin for providing contextual understanding. This work was supported by a Washington Global Health Alliance travel grant [2009 to DVC]; the Fogarty International Clinical Research Scholars and Fellows Program at Vanderbilt University [R24 TW007988 trainee support to DVC]; the National Cancer Institute [R25 CA094880 trainee support to DVC]; and the American Relief and Recovery Act. The funding sources played no role in the conception or writing of this research article. The corresponding author had final responsibility for the decision to submit for publication.

\section{Author details}

${ }^{1}$ Department of Epidemiology, University of Washington, Seattle, WA, USA. ${ }^{2}$ International Centre for Diarrheal Disease Research, Dhaka, Bangladesh. ${ }^{3}$ Department of Global Health, University of Washington, Seattle, WA, USA.

${ }^{4}$ Seattle University College of Nursing, Seattle, WA, USA.

Received: 18 November 2013 Accepted: 12 August 2014

Published: 15 August 2014

\section{References}

1. Sack DA, Sack RB, Nair GB, Siddique AK: Cholera. Lancet 2004, 363:223-233.

2. Morris JG: Cholera-modern pandemic disease of ancient lineage. Emerg Infect Dis 2011, 17:2099-2104.

WHO: Cholera, 2011. Wkly Epidemiol Rec 2012, 87:289-304.

4. WHO: Cholera, 2002. Wkly Epidemiol Rec 2003, 78:269-276. WHO: Cholera, 2010. Wkly Epidemiol Rec 2011, 86:325-339.

6. Ryan ET: The cholera pandemic, still with us after half a century: time to rethink. PLoS Negl Trop Dis 2011, 5:e1003.

7. Glass Rl, Becker S, Huq MI, Stoll BJ, Khan MU, Merson MH, Lee JV, Black RE: Endemic cholera in rural Bangladesh, 1966-1980. Am J Epidemiol 1982, 116:959-970.

8. Clemens J, Shin S, Sur D, Nair GB, Holmgren J: New-generation vaccines against cholera. Nat Rev Gastroenterol Hepatol 2011, 8:701-710.

9. Schwartz BS, Harris JB, Khan Al, Larocque RC, Sack DA, Malek MA, Faruque ASG, Qadri F, Calderwood SB, Luby SP, Ryan ET: Diarrheal epidemics in Dhaka, Bangladesh, during three consecutive floods: 1988, 1998, and 2004. Am J Trop Med Hyg 2006, 74:1067-1073.

10. Rahman KM, Duggal P, Harris JB, Saha SK, Streatfield PK, Ryan ET, Calderwood SB, Qadri F, Yunus M, LaRocque RC: Familial aggregation of Vibrio cholerae-associated infection in Matlab, Bangladesh. J Health Popul Nutr 2009, 27:733-738.

11. Harris JB, LaRocque RC, Chowdhury F, Khan Al, Logvinenko T, Faruque ASG, Ryan ET, Qadri F, Calderwood SB: Susceptibility to Vibrio cholerae infection in a cohort of household contacts of patients with cholera in Bangladesh. PLoS Negl Trop Dis 2008, 2:e221. 
12. Ali M, Emch M, Donnay JP, Yunus M, Sack RB: Identifying environmental risk factors for endemic cholera: a raster GIS approach. Health Place 2002, 8:201-210

13. Biswas DK, Bhunia R, Maji D, Das P: Contaminated pond water favors cholera outbreak at haibatpur village, purba medinipur district, west bengal. India J Trop Med 2014, 2014:764530.

14. You YA, Ali M, Kanungo S, Sah B, Manna B, Puri M, Nair GB, Bhattacharya SK, Convertino M, Deen JL, Lopez AL, Wierzba TF, Clemens J, Sur D: Risk map of cholera infection for vaccine deployment: the eastern Kolkata case. PLoS One 2013, 8:e71173.

15. Dunkle SE, Mba-Jonas A, Loharikar A, Fouché B, Peck M, Ayers T, Archer WR, De Rochars VMB, Bender T, Moffett DB, Tappero JW, Dahourou G, Roels T, Quick R: Epidemic cholera in a crowded urban environment, Port-au-Prince, Haiti. Emerg Infect Dis 2011, 17:2143-2146.

16. Izadi S, Shakeri H, Roham P, Sheikhzadeh K: Cholera outbreak in southeast of Iran: routes of transmission in the situation of good primary health care services and poor individual hygienic practices. Jpn J Infect Dis 2006, 59:174-178.

17. McCarthy N, Giesecke J: Case-case comparisons to study causation of common infectious diseases. Int J Epidemiol 1999, 28:764-768.

18. Wilson N, Baker M, Edwards R, Simmons G: Case-case analysis of enteric diseases with routine surveillance data: Potential use and example results. Epidemiol Perspect Innov 2008, 5:6.

19. Krumkamp R, Reintjes R, Dirksen-Fischer M: Case-case study of a Salmonella outbreak: an epidemiologic method to analyse surveillance data. Int J Hyg Environ Health 2008, 211:163-167.

20. Gillespie IA, O'Brien SJ, Frost JA, Adak GK, Horby P, Swan AV, Painter MJ, Neal KR: A case-case comparison of Campylobacter coli and Campylobacter jejuni infection: a tool for generating hypotheses. Emerg Infect Dis 2002, 8:937-942.

21. Ud-Din AIMS, Wahid SUH, Latif HA, Shahnaij M, Akter M, Azmi IJ, Hasan TN, Ahmed D, Hossain MA, Faruque ASG, Faruque SM, Talukder KA: Changing trends in the prevalence of Shigella species: emergence of multi-drug resistant Shigella sonnei biotype $\mathrm{g}$ in Bangladesh. PLoS One 2013, 8:e82601.

22. Hossain MA, Albert MJ, Hasan KZ: Epidemiology of shigellosis in Teknaf, a coastal area of Bangladesh: a 10-year survey. Epidemiol Infect 1990, 105:41-49.

23. Sack RB, Siddique AK, Longini IM, Nizam A, Yunus M, Islam MS, Morris JG, Ali A, Huq A, Nair GB, Qadri F, Faruque SM, Sack DA, Colwell RR: A 4-year study of the epidemiology of Vibrio cholerae in four rural areas of Bangladesh. $J$ Infect Dis 2003, 187:96-101.

24. Boyce JM, Hughes JM, Alim AR, Khan M, Aziz KM, Wells JG, Curlin GT: Patterns of Shigella infection in families in rural Bangladesh. Am J Trop Med Hyg 1982, 31:1015-1020.

25. Mosley WH, Benenson AS, Barui R: A serological survey for cholera antibodies in rural east Pakistan. 2. A comparison of antibody titres in the innunized and control populationd of a cholera-vaccine field-trial area and the relation of antibody titre to cholera case rate. Bull World Health Organ 1968, 38:335-346.

26. DuPont $\mathrm{HL}$, Levine MM, Hornick RB, Formal SB: Inoculum size in shigellosis and implications for expected mode of transmission. J Infect Dis 1989, 159:1126-1128.

27. Mosley WH, Adams B, Lyman ED: Epidemiologic and sociologic features of a large urban outbreak of shigellosis. JAMA 1962, 182:1307-1311.

28. Emch M: Diarrheal disease risk in Matlab, Bangladesh. Soc Sci Med 1999, 49:519-530

29. Colombara DV, Cowgill KD, Faruque ASG: Risk factors for severe cholera among children under five in rural and urban Bangladesh, 2000-2008: a hospital-based surveillance study. PLoS One 2013, 8:e54395.

30. Types of drinking-water sources and sanitation. [http://www.wssinfo.org/ definitions-methods/watsan-categories]

31. XE Currency Table: Mid-market rates as of 2004-07-01. [http://www.xe. com/currencytables/?from=USD\&date=2004-07-01]

32. Zou G: A modified poisson regression approach to prospective studies with binary data. Am J Epidemiol 2004, 159:702-706.

33. Greenland S: Dose-response and trend analysis in epidemiology: alternatives to categorical analysis. Epidemiology 1995, 6:356-365.

34. Steenland $\mathrm{K}$ : Smoothing is soothing, and splines are fine. Occup Environ Med 2005, 62:141-142.

35. Kosek M, Yori PP, Pan WK, Olortegui MP, Gilman RH, Perez J, Chavez CB, Sanchez GM, Burga R, Hall E: Epidemiology of highly endemic multiply antibiotic-resistant shigellosis in children in the Peruvian Amazon. Pediatrics 2008, 122:e541-e549.

36. Weil AA, Khan Al, Chowdhury F, Larocque RC, Faruque a SG, Ryan ET, Calderwood SB, Qadri F, Harris JB: Clinical outcomes in household contacts of patients with cholera in Bangladesh. Clin Infect Dis 2009, 49:1473-1479.

37. Levine MM, Nalin DR, Rennels MB, Hornick RB, Sotman S, Van Blerk G, Hughes TP, O'Donnell S, Barua D: Genetic susceptibility to cholera. Ann Hum Biol 1979, 6:369-374.

38. Giebultowicz S, Ali M, Yunus M, Emch M: A comparison of spatial and social clustering of cholera in Matlab, Bangladesh. Health Place 2011, 17:490-497.

39. Lin A, Arnold BF, Afreen S, Goto R, Huda TMN, Haque R, Raqib R, Unicomb L, Ahmed T, Colford JM, Luby SP: Household environmental conditions Are associated with enteropathy and impaired growth in rural Bangladesh. Am J Trop Med Hyg 2013, 89:130-137.

40. Ali M, Emch M, Park JK, Yunus M, Clemens J: Natural cholera infectionderived immunity in an endemic setting. J Infect Dis 2011, 204:912-918.

41. Albert MJ, Islam D, Nahar S, Qadri F, Falklind S, Weintraub A: Rapid detection of Vibrio cholerae 0139 Bengal from stool specimens by PCR. J Clin Microbiol 1997, 35:1633-1635.

doi:10.1186/1471-2334-14-440

Cite this article as: Colombara et al:: Risk factors for diarrhea hospitalization in Bangladesh, 2000-2008: a case-case study of cholera and shigellosis. BMC Infectious Diseases 2014 14:440.

\section{Submit your next manuscript to BioMed Central and take full advantage of:}

- Convenient online submission

- Thorough peer review

- No space constraints or color figure charges

- Immediate publication on acceptance

- Inclusion in PubMed, CAS, Scopus and Google Scholar

- Research which is freely available for redistribution

Submit your manuscript at www.biomedcentral.com/submit
C) BioMed Central 